\title{
ON AN ESTIMATION OF THE ROOTS OF ALGEBRAIC EQUATIONS
}

1. Introduction. In this paper we give a method for determining upper and lower bounds for the unique positive root of the equation

$$
x^{n}=\sum_{r=1}^{n} p_{r} x^{n-r} \quad\left(p_{r} \geqslant 0, r=1,2, \ldots, n\right)
$$

The knowledge of this root, or its upper bound, enables us to localize zeros of other polynomials with complex coefficients. This follows from the following theorem by Cauchy.

THEOREM. All zeros of the polynomial

$$
z^{n}+a_{1} z^{n-1}+\ldots+a_{n}
$$

with complex coefficients, lie in a circle

$$
|z| \leqslant R
$$

where $R$ is the positive root of the polynomial (1) with

$$
p_{k}=\left|a_{k}\right| \quad(k=1,2, \ldots, n) \text {. }
$$

This theorem plays an essential role in the majority of the known methods for finding a circular region enclosing all zeros of a polynomial. The method proposed here yields, in particular, the Westerfield bound [1] and makes it possible to find an upper bound, which is usually better than, and always at least as good as, the Westerfield bound. The proposed method gives also a lower bound for the positive root of (1).

2. The basic theorem. First, we shall prove some lemmas to be used in the sequel. 
LEMMA 1. If there is

then

$$
\begin{gathered}
\alpha_{j k} \geqslant 0 \quad(j=1,2, \ldots, m ; k=1,2, \ldots, n), \\
\sum_{k=1}^{n} \alpha_{j k}^{k} \leqslant M \quad(M>0 ; j=1,2, \ldots, m), \\
w_{j} \geqslant 0 \quad(j=1,2, \ldots, m), \quad \sum_{j=1}^{m} w_{j}=1,
\end{gathered}
$$

$$
\sum_{k=1}^{n}\left[\sum_{j=1}^{m} w_{j} \alpha_{j k}\right]^{k} \leqslant M
$$

The proof is by induction on $m$. Let $m=2$ and

$$
F(w)=\sum_{k=1}^{n}\left((1-w) \alpha_{1 k}+w a_{2 k}\right)^{k} .
$$

The second derivative of $F(w)$

$$
F^{\prime \prime}(w)=\sum_{k=2}^{n} k(k-1)\left(\alpha_{2 k}-\alpha_{1 k}\right)^{2}\left((1-w) \alpha_{1 k}+w a_{2 k}\right)^{k-2},
$$

is nonnegative for every $w \in[0,1]$ and so the function $F(w)$ is convex on $[0,1]$. On the other hand

$$
F(0)=\sum_{k=1}^{n} \alpha_{j k}^{k} \leqslant M \quad \text { and } \quad F(1)=\sum_{k=1}^{n} \alpha_{2 k}^{k} \leqslant M .
$$

Hence $F(w) \leqslant M$ for every $w \in[0,1]$.

Now we shall show that if the lemma holds for $m=p$, then it holds also for $m=p+1$ ( $p$ is a positive integer).

Let

$$
\sum_{j=1}^{p+1} w_{j}=1
$$

and $s$ be such that $1 \leqslant s \leqslant p+1$ and $w_{s}<1$. Next we define $B_{k}$ $(k=1,2, \ldots, n)$ by

$B_{k}$ satisfy the inequality

$$
\left(1-w_{s}\right) B_{k}=\sum_{\substack{j=1 \\ j \neq s}}^{p+1} w_{j} \alpha_{j k}
$$

$$
\sum_{k=1}^{n} B_{k}^{k}=\sum_{k=1}^{n}\left[\sum_{\substack{j=1 \\ j \neq s}}^{p+1} \frac{w_{j}}{1-w_{s}} \alpha_{j k}\right]^{k} \leqslant M .
$$


This follows from

$$
\sum_{\substack{j=1 \\ j \neq s}}^{p+1} \frac{w_{j}}{1-w_{s}}=1,
$$

and from the inductive supposition for $m=p$. Now

$$
\sum_{k=1}^{n}\left[\sum_{j=1}^{p_{+}+1} w_{j} \alpha_{j k}\right]^{k}=\sum_{k=1}^{n}\left(\left(1-w_{s}\right) B_{k}+w_{s} \alpha_{s k}\right)^{k}
$$

Since $\left(1-w_{s}\right)+w_{s}=1$, we conclude that

$$
\sum_{k=1}^{n}\left[\sum_{j=1}^{n+1} w_{j} \alpha_{j k}\right]^{k} \leqslant M
$$

which proves (3) for $m=p+1$.

LEMMA 2. If $H>0$ and $H^{n} \geqslant \sum_{r=1}^{n} p_{r} H^{n-r}$, then $H \geqslant x$, where $x$ is the unique positive root of the equation (1).

Proof. Let

$$
\varphi(y)=y^{n}-\sum_{r=1}^{n} p_{r} y^{n-r},
$$

$\varphi(y)<0$ for $0<y<x$ because $x$ is the unique positive root of the equation (1) and $\varphi(0) \leqslant 0$. Then from $\varphi(H) \geqslant 0$ and $H>0$ we have

$$
H \geqslant x \text {. }
$$

LeMma 3. Let $y_{m}$ be a positive root of the equation

$$
y^{m}=\sum_{r=1}^{m} y^{m-r}
$$

and let $y\left(n ; k_{1}, k_{2}, \ldots, k_{m}\right)$ be the unique positive root of the equation

$$
y^{n}=\sum_{r=1}^{m} y^{n-k_{r}}
$$

where $1 \leqslant k_{1}<k_{2}<\ldots<k_{m} \leqslant n$. Then

$$
y\left(n ; k_{1}, k_{2}, \ldots, k_{m}\right) \leqslant y m .
$$

Proof. From the definition

$$
y_{m}^{m}=\sum_{r=1}^{m} y_{m}^{m-r} .
$$


This implies

$$
y_{m}^{n}=\sum_{r=1}^{m} y_{m}^{n-r} .
$$

Since $y_{m} \geqslant 1$ and $r \leqslant k_{r}(r=1,2, \ldots, m)$, we can write

From lemma 2 follows

$$
y_{m}^{n} \geqslant \sum_{r=1}^{m} y_{m}^{n-k_{r}} .
$$

$$
y\left(n ; k_{1}, k_{2}, \ldots, k_{m}\right) \leqslant y_{m} .
$$

The basic result of this paper is the following

THEOREM 1. If $x_{j}$ are positive roots of the equations

$$
\begin{gathered}
x^{n}=a_{j 1} x^{n-1}+a_{j 2}^{2} x^{n-2}+\ldots+a_{j n}^{n} \\
\left(a_{j 1}, \ldots, a_{j n} \geqslant 0 ; j=1,2, \ldots, m\right),
\end{gathered}
$$

then the positive root $Z$ of the equation

satisfies the inequality

$$
x^{n}=\sum_{k=1}^{n}\left[\sum_{j=1}^{m} a_{j k}\right]^{k} x^{n-k}
$$

$$
Z \leqslant x_{1}+x_{2}+\ldots+x_{m}
$$

Proof. From the equality

$$
x_{j}^{n}=\sum_{k=1}^{n} a_{j k}^{k} x_{j}^{n-k}
$$

it follows that

$$
\sum_{k=1}^{n}\left[\frac{a_{j k}}{x_{j}}\right]^{k}=1
$$

From lemma 1, with $w_{j}=x_{j} /\left(x_{1}+x_{2}+\ldots+x_{m}\right)$ and $\alpha_{j k}=a_{j k} / x_{j}$, we obtain

$$
\begin{gathered}
\sum_{k=1}^{n}\left[\sum_{j=1}^{m} \frac{x_{j}}{x_{1}+x_{2}+\ldots+x_{m}} \frac{a_{j k}}{x_{j}}\right]^{k} \leqslant 1 \\
\sum_{k=1}^{n} \frac{\left[\sum_{j=1}^{m} a_{j k}\right]^{k}}{\left[\sum_{j=1}^{m} x_{j}\right]^{k}} \leqslant 1 \\
\sum_{k=1}^{n}\left[\sum_{j=1}^{m} a_{j k}\right]^{k}\left[\sum_{j=1}^{m} x_{j}\right]^{n-k} \leqslant\left[\sum_{j=1}^{m} x_{j}\right]^{n} .
\end{gathered}
$$


Now applying lemma 2, we get

$$
Z \leqslant \sum_{j=1}^{m} x_{j}
$$

which ends the proof of theorem 1.

3. Applications. One of the applications of theorem 1 is a new, very simple proof of the following theorem of Westerfield:

Theorem. Let $x_{0}$ be the unique positive root of the equation

$$
x^{n}=\sum_{k=1}^{n} p_{k} x^{n-k} \quad\left(p_{k} \geqslant 0, k=1,2, \ldots, n\right),
$$

and let positive quantities

$$
\sqrt[k]{p_{k}} \quad(k=1,2, \ldots, n),
$$

after being arranged in order of decreasing magnitudes, form a sequence

$$
q_{1} \geqslant q_{2} \geqslant \ldots \geqslant q_{n} \text {. }
$$

Then $x_{0}$ satisfies the inequality

where

$$
x_{0} \leqslant \sum_{k=1}^{n} q_{r} g_{r},
$$

$$
g_{1}=y_{1}, \quad g_{r}=y_{r}-y_{r-1} \quad(r=2,3, \ldots, n),
$$

and where $y_{k}$ is the unique positive root of the equation

$$
y^{k}=\sum_{r=1}^{k} y^{k-r} \quad(k=1,2, \ldots, n) .
$$

Proof. Apply theorem 1 to the equations

$$
x^{n}=\sum_{l=1}^{j}\left(q_{j}-q_{j+1}\right)^{k_{l}} x^{n-k_{l}} \quad(j=1,2, \ldots, n),
$$

where numbers $k_{l}$ are such that

$$
q_{l}=\sqrt[k_{l}]{p_{k_{l}}}
$$

and where $q_{n+1}=0$. We obtain

$$
\begin{aligned}
x_{0} \leqslant & \left(q_{1}-q_{2}\right) y\left(n ; k_{1}\right)+\left(q_{2}-q_{3}\right) y\left(n ; k_{1}, k_{2}\right)+\ldots \\
& \ldots+\left(q_{n-1}-q_{n}\right) y\left(n ; k_{1}, k_{2}, \ldots, k_{n-1}\right)+ \\
& +q_{n} y\left(n ; k_{1}, k_{2}, \ldots, k_{n}\right) .
\end{aligned}
$$


Hence by lemma 3

$$
\begin{aligned}
& x_{0} \leqslant\left(q_{1}-q_{2}\right) y_{1}+\left(q_{2}-q_{3}\right) y_{2}+\ldots+\left(q_{n-1}-q_{n}\right) y_{n-1}+q_{n} y_{n}= \\
& =q_{1} y_{1}+q_{2}\left(y_{2}-y_{1}\right)+\ldots+q_{n}\left(y_{n}-y_{n-1}\right)=q_{1} g_{1}+q_{2} g_{2}+\ldots+q_{n} g_{n},
\end{aligned}
$$

and this completes the proof.

Proceeding on a similar way, we can prove a generalization of Westerfield's theorem. Let $x_{0}$ be the unique root of the equation (1), and let $c_{1}, c_{2}, \ldots, c_{n}$ be arbitrary positive numbers. We arrange the quantities

$$
\sqrt[k]{c_{k} p_{k}} \quad(k=1,2, \ldots, n)
$$

in order of decreasing magnitudes:

$$
q_{1} \geqslant q_{2} \geqslant \ldots \geqslant q_{n} \text {. }
$$

Denote by $y\left(n ; R_{1}, R_{2}, \ldots, R_{m}\right)$ the positive root of the equation

$$
y^{n}=\sum_{j=1}^{m} \frac{1}{c_{R_{j}}} y^{n-R_{j}}
$$
where $1 \leqslant R_{1}<\ldots<R_{m} \leqslant n$. Let $y_{m}=\max _{R_{j}} y\left(n ; R_{1}, R_{2}, \ldots, R_{m}\right)$. We
shall prove the following

THEOREM 2. For any system of $n$ positive numbers $c_{1}, c_{2}, \ldots, c_{n}$

where

$$
x_{0} \leqslant \sum_{r=1}^{n} q_{r} g_{r}
$$

$$
g_{1}=y_{1}, \quad g_{r}=y_{r}-y_{r-1} \quad(r=2,3, \ldots, n) .
$$

Proof. Apply theorem 1 to the equations

$$
x^{n}=\sum_{l=1}^{j} \frac{1}{c_{k_{l}}}\left(q_{j}-q_{j+1}\right)^{k_{l}} x^{n-k_{l}} \quad(j=1,2, \ldots, n),
$$

where numbers $k_{l}(l=1,2, \ldots, n)$ are such that

and $q_{n+1}=0$. We obtain

$$
q_{l}=\sqrt[k l]{c_{k l} p_{k l}}
$$

$$
\begin{aligned}
x_{0} \leqslant & \left(q_{1}-q_{2}\right) y\left(n ; k_{1}\right)+\left(q_{2}-q_{3}\right) y\left(n ; k_{1}, k_{2}\right)+\ldots \\
& \ldots+\left(q_{n-1}-q_{n}\right) y\left(n ; k_{1}, k_{2}, \ldots, k_{n-1}\right)+q_{n} y\left(n ; k_{1}, k_{2}, \ldots, k_{n}\right) \\
& \leqslant\left(q_{1}-q_{2}\right) y_{1}+\left(q_{2}-q_{3}\right) y_{2}+\ldots+\left(q_{n-1}-q_{n}\right) y_{n-1}+q_{n} y_{n} \\
& =q_{1} y_{1}+q_{2}\left(y_{2}-y_{1}\right)+\ldots+q_{n}\left(y_{n}-y_{n-1}\right)=q_{1} g_{1}+q_{2} g_{2}+\ldots+q_{n} g_{n}
\end{aligned}
$$

which ends the proof of theorem 2. 
In the special case $c_{r}=1(r=1,2, \ldots, n)$, we obtain the Westerfield bound.

Theorem 2 suggests a question. Let $W$ be the set of all equations (1) with the root 1 . Denote by $F\left(c_{1}, c_{2}, \ldots, c_{n}: r\right)$ the bound resulting from theorem 2 for fixed $c_{1}, c_{2}, \ldots, c_{n}$ and $r \epsilon W$. Let

$$
H\left(c_{1}, c_{2}, \ldots, c_{n}\right)=\sup _{r \in W} F\left(c_{1}, c_{2}, \ldots, c_{n} ; r\right) .
$$

Now the question is, for what system of $c_{r}(r=1,2, \ldots, n) H\left(c_{1}, c_{2}, \ldots, c_{n}\right)$ is minimal.

Another application of theorem 1 gives a lower bound for the unique positive root of equation (1). Using the same notation as in Westerfield's theorem, we shall state the following

Theorem 3.

$$
x_{0} \geqslant \sum_{r=1}^{n} q_{r} g_{n+1-r} .
$$

Proof. Let $y$ be the positive root of equation

$$
x^{n}=\left(q_{1}-p_{1}\right) x^{n-1}+\left(q_{1}-\sqrt{p_{2}}\right)^{2} x^{n-2}+\ldots+\left(q_{1}-\sqrt[n]{p_{n}}\right)^{n} .
$$

Since $q_{1} y_{n}$ is the positive root of the equation

$$
x^{n}=\sum_{k=1}^{n} q_{\mathrm{l}}^{k} x^{n-k},
$$

then, applying theorem 1 , it is easy to see that

$$
q_{1} y_{n} \leqslant x_{0}+y .
$$

From Westerfield's theorem, we have

$$
\begin{aligned}
y & \leqslant\left(q_{1}-q_{n}\right) g_{1}+\left(q_{1}-q_{n-1}\right) g_{2}+\ldots+\left(q_{1}-q_{2}\right) g_{n-1} \\
& =q_{1} y_{n-1}-\sum_{r=2}^{n} q_{r} g_{n+1-r} .
\end{aligned}
$$

Hence

$$
\begin{gathered}
q_{1} y_{n} \leqslant x_{0}+q_{1} y_{n-1}-\sum_{r=2}^{n} q_{r} g_{n+1-r}, \\
x_{0} \geqslant \sum_{r=2}^{n} q_{r} g_{n+1-r}+q_{1}\left(y_{n}-y_{n-1}\right)=\sum_{r=1}^{n} q_{r} g_{n+1-r},
\end{gathered}
$$

and so the theorem is proved. 
An example. Applying theorem 3 to the equation

$$
x^{3}=x^{2}+3 x+9
$$

with the positive root $x=3$ we obtain

$$
x \geqslant 2,52 \text {. }
$$

By Westerfield's theorem, applied to the equation

$$
\frac{1}{y^{3}}=\frac{1}{y^{2}}+3 \frac{1}{y}+9
$$

we have

$$
y \leqslant 0.9
$$

Since $1 / x=y$, hence $x \geqslant 1.11$.

Now, we shall generalize theorem 3 in the same way as Westerfield's theorem.

Generalization of THEOREM 3. Let $x_{0}, g_{r}, q_{r}$ and $c_{r}(r=1,2, \ldots, n)$ be defined as in theorem 2. Then

$$
x_{0} \geqslant \sum_{r=1}^{n} q_{r} g_{n+1-r} .
$$

Proof. Denote by $y$ the positive root of the equation

$$
x^{n}=\sum_{k=1}^{n}\left[\frac{q_{1}}{\sqrt[k]{c_{k}}}-\sqrt[k]{p_{k}}\right]^{k} x^{n-k} .
$$

Applying theorem 1, we get

By theorem 2

$$
q_{1} y_{n} \leqslant x_{0}+y .
$$

$$
y \leqslant \sum_{r=2}^{n}\left(q_{1}-q_{r}\right) g_{n+1-r}
$$

hence

$$
q_{1} y_{n}-\sum_{r=2}^{n}\left(q_{1}-q_{r}\right) g_{n+1-r} \leqslant x_{0}, \quad \sum_{r=1}^{n} q_{r} g_{n+1-r} \leqslant x_{0}
$$

In the proof of Westerfield's theorem we have obtained the inequality

$$
\begin{aligned}
x_{0} \leqslant\left(q_{1}-q_{2}\right) & y\left(n ; k_{1}\right)+\left(q_{2}-q_{3}\right) y\left(n ; k_{1}, k_{2}\right)+\ldots \\
& +\left(q_{n-1}-q_{n}\right) y\left(n ; k_{1}, k_{2}, \ldots, k_{n-1}\right)+q_{n} y\left(n ; k_{1}, k_{2}, \ldots, k_{n}\right) .
\end{aligned}
$$

This bound is better, or at least not worse, than Westerfield's bound. 
To ilustrate the use of inequality (4), we may apply it to the equation (5)

$$
x^{9}=x^{8}+512 x^{6}+16 x^{5}+16807 x^{4}+x^{2}+1 .
$$

In this case we have

$$
\begin{aligned}
& n=9, \quad q_{1}=8, \quad q_{2}=7, \quad q_{3}=2, \quad q_{4}=q_{5}=q_{6}=1, \\
& q_{7}=q_{8}=q_{9}=0, \quad k_{1}=3, \quad k_{2}=5, \quad k_{3}=4, \quad k_{4}=9, \\
& k_{5}=7, \quad k_{6}=1,
\end{aligned}
$$

so we get

Since

$$
x_{0} \leqslant y(9 ; 3)+5 y(9 ; 3,5)+y(9 ; 3,5,4)+y(9 ; 3,5,4,9,7,1) .
$$

then

$$
\begin{aligned}
& y(9 ; 3)=1, \\
& y(9 ; 3,5)<1.21, \\
& y(9 ; 3,5,4)<1.33, \\
& y(9 ; 3,5,4,9,7,1)<1.98,
\end{aligned}
$$

$$
x_{0}<10.36 \text {. }
$$

Applying Westerfield's method we obtain

Actually we have

$$
x_{0}<13 \text {. }
$$

$$
x_{0} \approx 9.265 .
$$

To simplify the application of inequality (4), we provide the reader with a table of the positive roots of the equations:

$$
y^{n}=\sum_{r=1}^{m} y^{m-r}
$$

for $m=2,3, \ldots, n$ and $n=2,3, \ldots, 10$.

TABLE of the roots $y(n ; n-1, \ldots, n-m+1)$

\begin{tabular}{r|ccccccccc}
\hline$n$ & 10 & 9 & 8 & 7 & 6 & 5 & 4 & 3 & 2 \\
\hline 10 & 1.999 & & & & & & - & & \\
9 & 1.612 & 1.998 & & & & & & & \\
8 & 1.451 & 1.608 & 1.997 & & & & & & \\
7 & 1.355 & 1.444 & 1.602 & 1.992 & & & & & \\
6 & 1.286 & 1.343 & 1.432 & 1.590 & 1.984 & & & & \\
5 & 1.230 & 1.269 & 1.325 & 1.413 & 1.571 & 1.966 & & & \\
4 & 1.180 & 1.207 & 1.244 & 1.297 & 1.381 & 1.535 & 1.928 & & \\
3 & 1.131 & 1.149 & 1.172 & 1.204 & 1.250 & 1.325 & 1.466 & 1.840 & \\
2 & 1.076 & 1.086 & 1.097 & 1.113 & 1.135 & 1.168 & 1.220 & 1.325 & 1.610
\end{tabular}


These roots may be used as upper bounds for the roots

$$
y\left(n ; k_{1}, k_{2}, \ldots, k_{m}\right) \quad(n \leqslant 10) .
$$

In fact, it is easy to see that

$$
y\left(n ; k_{1}, k_{2}, \ldots, k_{m}\right) \leqslant y(s ; s, s-1, \ldots, s-m+1),
$$

where $s=j+m-1$ and $j=\min \left(k_{1}, k_{2}, \ldots, k_{m}\right)$.

An example. We apply it to the equation (5). Since

$$
\begin{aligned}
& y(9 ; 3)=1, \\
& y(9 ; 3,5)<y(4 ; 4,3)<1.220, \\
& y(9 ; 3,5,4)<y(5 ; 5,4,3)<1.325, \\
& y(9 ; 3,5,4,9,7,1)<y(6 ; 6,5,4,3,2,1)<1.984,
\end{aligned}
$$

then

$$
x_{0}<10.409 \text {. }
$$

The bound (4) for the positive root of equation

$$
x^{n}=q_{n} x^{n-1}+q_{n-1}^{2} x^{n-2}+\ldots+q_{1}^{n},
$$

where $n \leqslant 8$ and $q_{1} \geqslant q_{2} \geqslant \ldots \geqslant q_{n}$, is

$$
\begin{aligned}
x_{0} \leqslant \delta_{1}+1.097 \delta_{2}+1.172 \delta_{3}+1.244 \delta_{4}+1.325 \delta_{5} & +1.432 \delta_{6}+ \\
& +1.602 \delta_{7}+1.997 \delta_{8},
\end{aligned}
$$

where $\delta_{i}=q_{i}-q_{i+1}(i=1,2, \ldots, 7)$ and $\delta_{8}=q_{8}$. For Westerfield's bound we obtain

$$
\begin{aligned}
x_{0} \leqslant \delta_{1}+1.619 \delta_{2}+1.840 \delta_{3}+1.928 \delta_{4}+1.966 \delta_{5} & +1.984 \delta_{6}+ \\
& +1.992 \delta_{7}+1.997 \delta_{8} .
\end{aligned}
$$

\section{Reference}

[1] E. C. Westerfield, $A$ new bound for thd zeros of polynomials, Amer. Math. Monthly 40 (1933), pp. 18-23.

Received on 15. 6. 1968

\section{B. BOJANOV (Wroclaw)}

\section{SZACO WANIE PIER WIASTKó W Ró WNAN ALgebRAICZNYCH}

\section{STRESZCZENIE}

Opisano metode szacowania $\mathrm{z}$ góry dodatniego pierwiastka równania (1) za pomoca dodatnich pierwiastków równań tego samego typu (twierdzenie 1). Podano nowy dowód twierdzenia Westerfielda [1] i pewne jego uogólnienie (twierdzenie 2). 
Otrzymana nierówność (4) pozwala uzyskać oszacowania lepsze, albo przynajmniej nie gorsze, niż oszacowanie Westerfielda. Uzyskano również oszacowanie z dołu dodatniego pierwiastka równania (1).

\section{Б. БО Я НО В (Вроцлав)}

\section{ОБ ОЦЕНКЕ КОРНЕЙ АЛГЕБРАИЧЕСКИХ УРАВНЕНИЙ}

\section{P E 3 Ю M E}

В работе описан метод оценки сверху положительного корня уравнения (1) с помощью положительных корней уравнений того же вида (теорема 1). Дается новое доказательство теоремы Вестерфилда [1] и ее обобщение (теорема 2). Из полученного неравенства (4) вытекают оценки корней, которые лучше или по крайней мере не хуже оценок Вестерфилда. Получена такж е оценка снизу положительного корня уравнения (1). 